\title{
Elderly-technology interaction: accessibility and acceptability of technological devices promoting motor and cognitive training.
}

\author{
Tiziana C. Callari ${ }^{\mathrm{a},{ }^{*}}$, Silvia Ciairano ${ }^{\mathrm{b}}$ and Alessandra Re ${ }^{\mathrm{a}}$ \\ ${ }^{a}$ LIDEA-InterDepartmental Laboratory of Applied Ergonomics, Department of Psychology, Università degli Studi \\ di Torino, Via Verdi 10, 10124 Torino, Italy \\ ${ }^{\mathrm{b}}$ Laboratory of Developmental Psychology, Department of Psychology, Università degli Studi di Torino
}

\begin{abstract}
As the world population is ageing, studies on the socio-economic and health consequences are proliferating. Little has been done on the effectiveness and impact elderly may benefit from the use of technology in their everyday life. The pilot study, implemented within a funded project aimed at identifying sustainable actions to promote Seniors' quality of life, intended to investigate this kind of interaction in terms of accessibility and acceptability that senior citizen experience with technological devices promoting motor and cognitive training. In the hypothesis, interfaces and technological artifacts, that still take in little account the seniors' physical characteristics (e.g. physiological limitations in sight, hearing, movement) and cognitive processes (selective memory often driven by practical needs), can cause elderly to mistrust technology. Study participants were twenty over seventy-year-old people, who were observed and interviewed in context in a two-hour training session regarding the technological devices user experience. The results are presented with scenario-based techniques that help represent typologies of users in different use situations. Findings confirm the hypothesis, highlighting that elderly may accept technological artifacts when they perceive them as bringing benefits in terms of well-being and health.
\end{abstract}

Keywords: ageing; quality of life; usability; interaction design

\section{Introduction}

Population ageing is widespread across the world and it is associated with socio-economic outcomes on the welfare state and in particular on the social security systems - and health consequences among which, decline in cognitive abilities, life skills, quality of life. Several studies have shown that senior citizens' decline of physical and psychological skills is not unavoidable. The more an active lifestyle, continuous brain exercise and physical training is practiced, the more cognitive and mobility decline seems to be tackled. Together with well-experimented practices like social service, cultural and outdoor activities, nowadays everybody has the opportunity to train mind and body with different technological solutions already available on the market. But how far are these technological solutions accessible to older people? Are these technologies acceptable for the needs and resources of the elderly?

The present study aimed to investigate to what extent elder people access and make use of cognitive and physical training devices, such as "balance boards" and "memory games", as alternative solutions to maintain their body and mind in shape. The study was developed within a multidisciplinary project sponsored by the Piedmont Region, "Act on Ageing" (http://www.actonageing.eu/), whose main goal was to identify sustainable actions to promote the Seniors' quality of life through action-research interventions on the relationship between physical activity, memory and everyday abilities in seniors. "Act on Ageing" involved a co-operation between the University, local key stakeholders (trainers, ONGs, practi-

${ }^{*}$ Corresponding author. E-mail: tiziana.callari@unito.it, Tel +39011670.2805 
tioners, physicians, etc.), and about 300 elder people in the implementation of motor and cognitive programs, workshops and game activities, and in the results evaluation.

The following hypotheses were formulated:

- interfaces and technological artifacts that still take in little account the seniors' physical characteristics (e.g. physiological limitations in sight, hearing, movement) and cognitive processes (selective memory often driven by practical needs), can cause elderly to mistrust technology;

- secondly, the elderly may accept technological artifacts when they perceive them as bringing benefits in terms of well-being and health.

The study followed the User-Centered Design principles [1], involving the target users (elder people) and the project stakeholders (NGOs Seniors representatives, motor trainers, psychologists, etc.) in the whole process development.

The study was implemented in the period MaySeptember 2011.

\section{Elderly and technology}

There is unanimous agreement that regular physical $[2,3,4,5]$ and cognitive $[6,7,8,9,10]$ exercises contribute to healthy ageing. Numerous studies have demonstrated that cognitive training can stimulate mnemonic capacities, attention, and planning, even if seriously impaired due to the onset of ageing diseases, such as dementia. It is assumed that physical and cognitive stimulation can modulate synaptic activity and the brain plasticity $[11,12]$. These considerations suggest that combining physical and cognitive training could have a synergistic effect leading to faster and/or stronger outcomes, including societal and quality of life benefits.

Among the many recreational outdoor and indoor activities designed to support senior citizens maintaining physical and mental health, nowadays several technological solutions are available, which pay particular attention to cognitive, social and health needs [13]. The market of technology is changing all the time, and new devices are constantly designed for the purpose. Many studies show how elderly are more and more accustomed to (new) technologies, not only in the daily use of domestic appliances, but also regularly surfing the net, using the PC, and playing different game devices. In Italy the situation is changing for the better, showing a rapidly growing trend of older people using PC and ICT [14].
The ergonomic [15] and gerontechnology [16] approach can improve the elderly-technology relation. Starting from the 1990s the gerontechnology, which has been developed within a Man-Machine perspective [16], has aimed to design advanced technological solutions to support cognitive and physical monitoring, and to fulfill the needs of an ageing society. The market already offers several handy-gaming devices that aim to improve cognitive skills. Indeed, video games have been demonstrated to be useful to train attention and perception in young adults as well as in elderly people [17]. The games offer complex scenarios that can stimulate discussion, collaboration and imagination, or fundamental skills such as hand-eye coordination, strategic abilities and problem solving $[18,19,20]$ Physical training devices have been implemented by therapists for a range of motor injuries [21, 22], pathologies [23] and management of elderly care $[24,25]$ while balance board devices are available for different leisure opportunities.

Taking these market solutions into account, to what extent do the elderly effectively access to and accept the on-market-available technological artifacts to improve their quality of life by exercising their motor abilities and cognitive skills?

Accessibility to technology is intended whatever information, availability or use of technical devices that are adequate for the needs and abilities of older people [26]. Accessibility is about a more sensitive approach to people with a disability, awareness of the person's needs and feelings, understanding and acceptance, and the creation of an inclusive environment. Problems of accessibility especially emerge for the elderly when habitual behaviors have to be changed, or when a devise requires totally new courses of action. The European Commission's "eAccessibility" program $^{2}$ aims to ensure people with disabilities and elderly people access ICTs on an equal basis, removing the barriers they encounter when trying to access and use ICT products, services and applications.

Acceptance of technology involves individual necessities and financial resources, a crucial precondition for the acquisition and use of appliances [27]. Acceptability does not depend only on the concrete and certain benefits the technological device offers to the user, or on the perceived usefulness of its support, but also on the complex relationships it activates between cognitive, affective and emotional responses [28]. Often elderly seek for technological alternatives

\footnotetext{
${ }^{2}$ For further information: http://ec.europa.eu/information_society/activities/einclusion/policy /accessibility/index en.htm
} 
to solve the problems they have to cope with, in performing everyday activities.

\section{Method}

\subsection{Participants}

A group of 20 elderly were recruited among the project's target group. The participants were categorized according to gender (F-email vs. M-ale); age (at the date of intervention); level of study $(1=$ no title; $2=$ primary school; $3=$ secondary school; $4=$ professional diploma; $5=$ degree); job before retiring; level of ICT confidence (assigning 1=little to $4=$ much) (Table 1).

Table 1

Participants to the pilot study

\begin{tabular}{|l|l|l|l|l|l|}
\hline ID & Gender & Age & $\begin{array}{l}\text { Level of } \\
\text { study }\end{array}$ & $\begin{array}{l}\text { Job before } \\
\text { retiring }\end{array}$ & $\begin{array}{l}\text { Level of ICT } \\
\text { confidence }\end{array}$ \\
\hline P01 & F & 71 & 2 & $\begin{array}{l}\text { FIAT } \\
\text { worker }\end{array}$ & 2 \\
\hline P02 & F & 77 & 3 & nurse & 1 \\
\hline P03 & F & 72 & 3 & secretary & 3 \\
\hline P04 & F & 73 & 1 & housewife & 2 \\
\hline P05 & F & 73 & 2 & $\begin{array}{l}\text { shop hel- } \\
\text { per }\end{array}$ & 1 \\
\hline P06 & F & 74 & 2 & housewife & 2 \\
\hline P07 & F & 73 & 4 & hairdresser & 2 \\
\hline P08 & F & 77 & 1 & $\begin{array}{l}\text { health } \\
\text { worker }\end{array}$ & 1 \\
\hline P09 & F & 73 & 3 & $\begin{array}{l}\text { FIAT } \\
\text { worker }\end{array}$ & 3 \\
\hline P10 & F & 75 & 1 & housewife & 2 \\
\hline P11 & F & 73 & 2 & worker & 2 \\
\hline P12 & F & 73 & 3 & farmer & 1 \\
\hline P13 & F & 70 & 2 & employee & 4 \\
\hline P14 & F & 72 & 3 & nurse & 2 \\
\hline P15 & M & 70 & 3 & employee & 3 \\
\hline P16 & M & 73 & 2 & worker & 3 \\
\hline P17 & M & 71 & 4 & $\begin{array}{l}\text { FIAT } \\
\text { employee }\end{array}$ & 4 \\
\hline P18 & M & 71 & 4 & $\begin{array}{l}\text { fiat } \\
\text { worker }\end{array}$ & 3 \\
\hline P19 & M & 73 & 3 & farmer & 2 \\
\hline P20 & M & 75 & 2 & worker & 3 \\
\hline & & & & & \\
\hline
\end{tabular}

\subsection{Procedure}

The user-centered design approach [29, 30] guided the research design, involving in all steps the keystakeholders and the target seniors [31].
The participants were asked to use physical training devices and memory games with portable console (Picture 1), in order to test and comment them.

Picture 1. Devices used during the training sessions
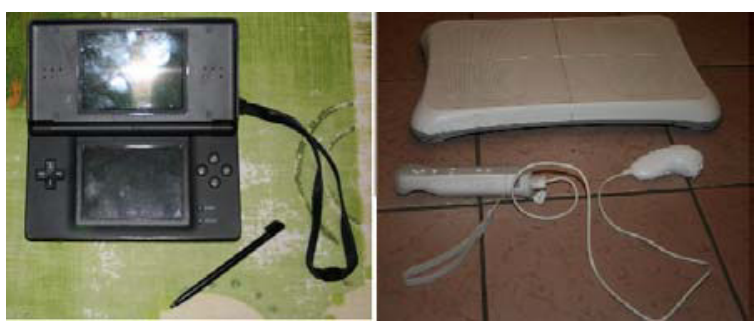

The study was developed during the project motor training workshops (once a week at the local sports halls) (Pictures 2-3), asking the participants to use for the day the physical device instead (Picture 4).
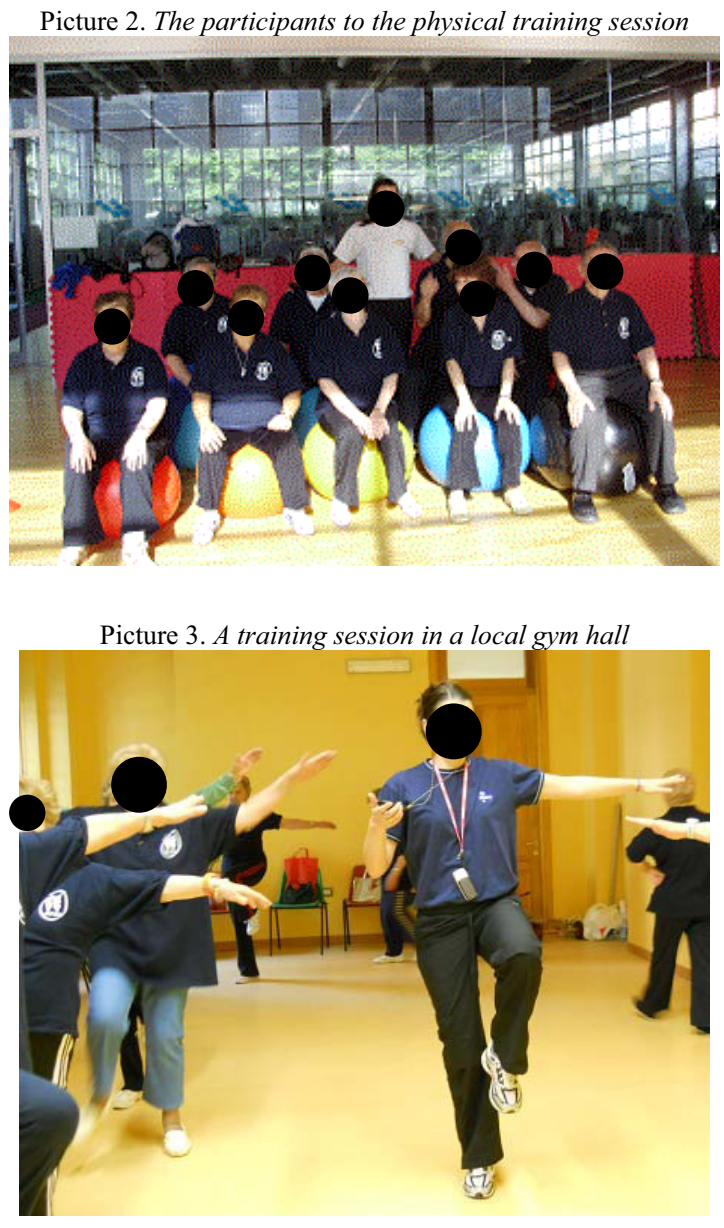
Picture 4. Female participant training with the balance board

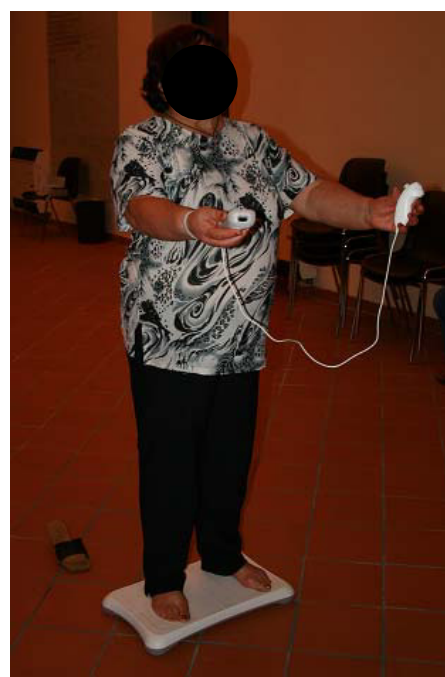

The cognitive training was implemented sometimes at the participants' home (Picture 5), but usually at the University during the specific project cognitive workshops.

Picture 5. Male Participant training with the DS

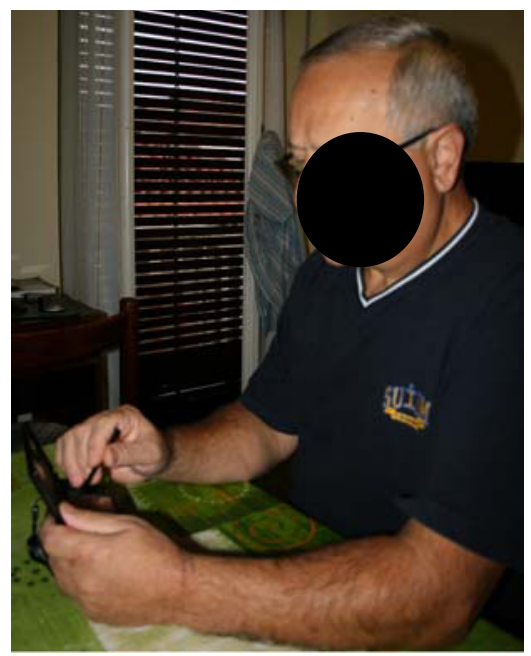

The following techniques were used during the participants' interaction with the technology [32], to uproot the accessibility and acceptability elements of the available technology during the use experience and highlight the usability requirements [33]:

- Direct observations [34, 35]. Observations were finalized to capture the adopted behaviors during the use, thinking aloud comments (recording expression of joy and/or frustration during the use), trials and errors in the exercise application, scores and final assessments by the users.

- Contextual inquiries [36]. It is a technique to gather data from users performing specific tasks in a specific context. During the motor ad cognitive interaction with the devices, at the participants' home (in what room?; is there enough space?), the inquiries were meant to uproot aspects relevant for the existing vs. the to-be technology usage, such as perceived advantages and disadvantages, possible situations/scenarios of interaction with the devices.

- In-depth interviews [37, 38], focusing on the following aspects: participants life styles, such as interests, state of health, social network, etc.; general level of ICT confidence; personal reasons for technological device(s) choice; opinions on to what extent the technological device(s) may change one's life.

The inquiries and interviews were tape-recorded and integrally transcribed. When agreed, pictures and videos focusing on specific moments of interaction were recorded. The general ethical considerations were ensured.

\subsection{Data analysis}

The data collected were analyzed with the support of N-Vivo, a qualitative data analysis software, that helped categorize the pictures, videos and documental texts under the two macro nodes of research interest, $<<$ Accessibility $>>$ and $<<$ Acceptability $>>$.

\section{Results}

The converging use of different techniques (triangulation) [37] allowed to identify multiple levels of interactions.

At a physical interaction level, it emerged a polarized use of the device from two different categories of elderly: the first group was made of elder people who practiced sport activities in the past and keep on practicing; the second group included seniors who do not practice any physical activity. While in the first case the device was able to bring up the participants' already acquired motor-sensorial schemes, with a visible confidence in the use of the technology; in the second case even the little height balance board's difference brought to a discomfort perception and loose of balance. 
In addition, the second group also showed a high level of discomfort in the fine motor skills and dexterity required for the interaction with cognitive games devices (Picture 5). Their frustration was indicated aloud - P04: "I don't get it"; P12: "What should I press"; P10: "I cannot go on"; etc. - with facial expressions, in the motions of fingers and hands, finding hard to execute the cognitive tasks.

Picture 6. Female Participant with low dexterity

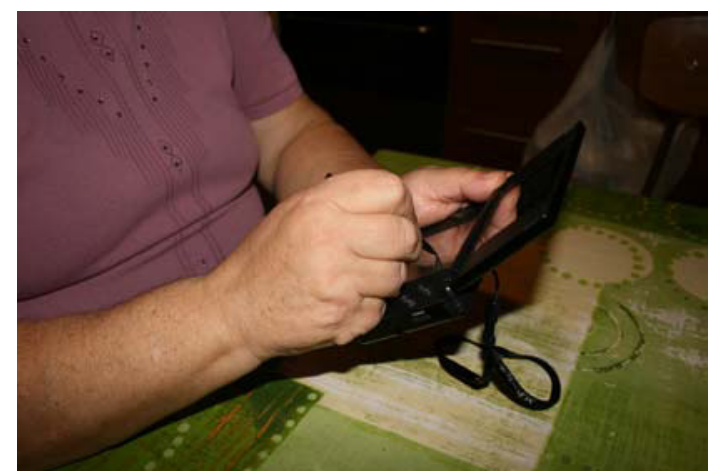

The data from the contextual inquiries and interviews have been analyzed following the Personas [39] and Scenario-based techniques [40, 41, 42], to highlight the different situations in which the elder people perform motor and cognitive exercises with technological devices, keeping the focus on the accessibility and acceptability principles.

The Personas technique helped to design two polarized personas representing the two opposite groups identified in the physical interaction:

Persona 1

Paolo has just turned the 70 years birthday. He is curious
about the coaching activities implemented within the "Act
On Ageing" project and the opportunities to train his skills
cold and an indoor environment, when outside is winter or
exercise.

Persona 2

Luisa is an over 70-year old housewife who never practiced sport, apart from the routine housekeeping. She perceives herself clumsy with hands during the tasks execution with the device. She keeps on excusing herself for her difficulties and she feels sorry for every failure during the interaction with the technology.

Each Persona has been considered in Scenarios [5] that came up from the interviews with the study par- ticipants, according to a Persona-Scenario compatibility assessed by two independent judges.

Scenario 1

"Paolo: challenging friends at golf in the garage"

Paolo lives with his wife in a nice villa $20 \mathrm{~km}$ far from Turin. Gardens, green and fresh hair is the environment. Paolo loves fresh air and sports outdoor. Fortunately he has always had the possibilities to practice outdoor sports, like horse riding and golf. He has maintained during the years friends and colleagues to share his interests with. Last Christmas his only-child gave him a console with a golf simulation applica-

tion. Paolo welcomed it with enthusiasm and started playing it almost every day, driving his wife crazy $<$ Should you play that here, in the dining room, there's plenty of place outside..even in the garage! Go play there!>. In less than a month Paolo re-organized the empty garage for the game, inviting his friends and colleagues home for long-lasting competitions. In February, unfortunately, a little injury happened to one of Paolo's friends that made him reconsider the use of the game: during a simulation movement of hitting the ball with the club, Paolo's friend tear his arm's muscle. The doctor said that older people need to balance strength and movement more than youngest, and most of sports games do not take this physical constraint into account when designing the game. Games are designed to be practiced by people in shape, not for specific target group with potential disabilities or motor limitations.

Picture 7 shows the scenario [41] referred to Paolo-Persona.

Picture 7. Paolo playing in the Scenario 1

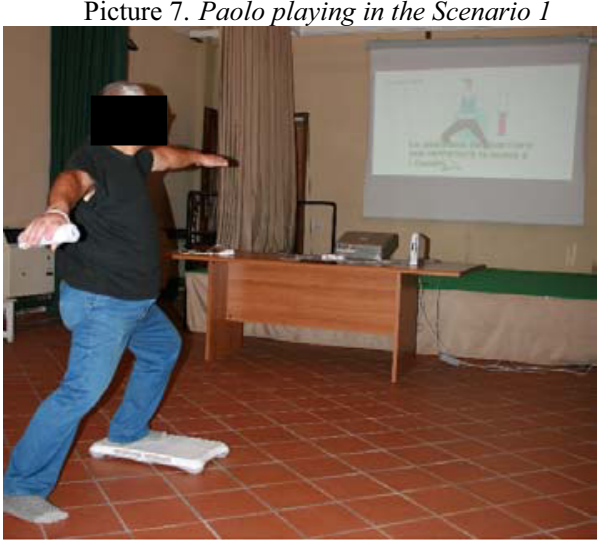

The results show the direct relation between a user-friendly device perception and a motivation to use. A motivation that can lead to a game overuse and consequent hazards for the personal health. The trainers and project coachers frequently highlighted these hazards and trained the way to cope with them, in a safety use of the device. 
The second group, who showed greater difficulties in the interaction, assessed the training as not useful and consequently expressed no interest for a future use.

The results confirmed the hypotheses: the elderly are keen to use technological devices with greater motivation when they perceive them as user-friendly and when they actually believe that the technology will improve their health and safety. The lack of a perceived benefit is the primary barrier to a wider use of interactive IT technologies.

It seems not to exist a significant correlation between the title of study and the interest/inclination to use technology.

The technology seems to bring a connotation as "facilitator" to the seniors' interests and activities (e.g. train the body to prepare it for an excursion to the nature), and not as a mere alternative that could reduce the social aspect of the physical activities usually performed. The participants declare that they do not want to get isolated and modify their basic social rules - meet you in person to share leisure interests $v s$. practice by myself with the simulator-game.

During the training sessions with the motor and cognitive devices the use of the feedback on the performance resulted very important for the participants. During the training sessions with motor trainers and cognitive psychologists, the participants showed a greater motivation and interest for device use when the interactive systems provided timely tailored feedback and advice, and often looked for tracks of performance trends.

Seniors demonstrated a preference for technological devices that could provide them with information specifically tailored, and that can fit into their normal daily routine.

\section{Conclusions}

Not much has been explored on the elderlytechnology interaction regarding the use of cognitive and/or motor training devices. These happen to be used mostly by youngest and families with children and adolescents, rather than older people-target group. Marketing communications and game appliances seem to follow the anthropometric and biomechanics of the young-average person. Little has still be done for the specific target user of seniors.

The cost represents a limit that may prevent from buying it as part of the domestic "devices" useful for specific training, even when required by doctors; gym halls where meeting new people and friends keep to be preferred.

More should be invested to introduce (and educate) older people, currently excluded, to technology use (the so-called e-inclusion). Some suggestions may take into account:

- Community demonstrators: free installations in public places where users may try and/or watch the potential benefits of the promoted device.

- Health support: the elderly should be provided with free-of-charge devices when specific motor training exercises are suggested by doctors.

- Usability principles: more should be invested by designers and providers in terms of usability for the specific target group of seniors. Userfriendly design for older people with specific physical characteristics (e.g. physiological limitations in sight, hearing, movement) and cognitive processes (selective memory often driven by practical needs), should be also considered. For example elderly with motor impairment find it difficult to step up the balance board and correctly use it (Picture 8). Issues of access, ease of use, and convenience of technology systems were also found to be key barriers to wider use.

Picture 8. Elder male person with feet motor impairment

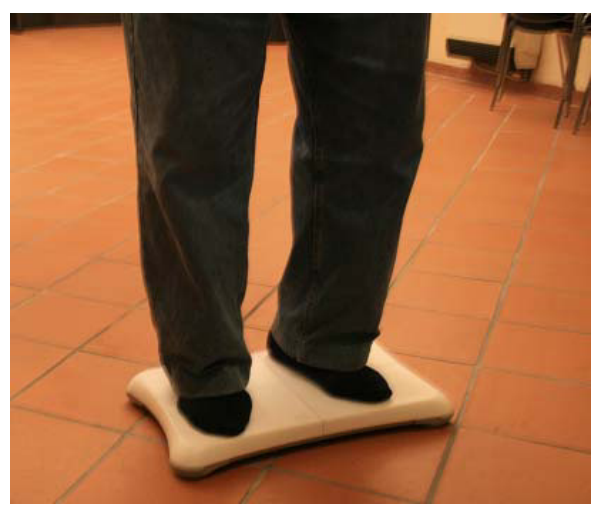

In general, technologies seem to be designed still following a technology driven approach, rather than a user-centered design one. Designers and providers should keep track of the socio-demographic, economical and cultural changes, and consider the elderly as a valuable target to be studied, approached, convinced and "acquired". Without forgetting that the confident and technologically - experienced users of today will be the seniors of tomorrow. 


\section{Acknowledgements}

The authors would like to thank the Directorate of Research and Innovation of the Piedmont Region for sponsoring this research. Further, the authors would like to thank the research group coordinated by Prof. Silvia Ciairano, Project Manager of "Act On Ageing" for the effective support in getting in touch with the project target group, and research members of LIDEA for their contribution in research data collection and analysis.

\section{References}

[1] ISO 18529/2000.

[2] Angevaren, M., Aufdemkampe, G., Verhaar, H. J., Aleman, A., \& Vanhees, L. (2008). Physical activity and enhanced fitness to improve cognitive function in older people without known cognitive impairment. Cochrane Database Syst $\operatorname{Rev}(2)$, CD005381.

[3] Oreopoulos, A., Kalantar-Zadeh, K., Sharma, A. M., \& Fonarow, G. C. (2009). The Obesity Paradox in the Elderly: Potential Mechanisms and Clinical Implications. Clinics in Geriatric Medicine, 25(4), 643-659.

[4] Erickson, K. I., Prakash, R. S., Voss, M. W., Chaddock, L., Hu, L., Morris, K. S., et al. (2009). Aerobic fitness is associated with hippocampal volume in elderly humans. Hippocampus, 19(10), 1030-1039.

[5] Stahle, A., Mattsson, E., Ryden, L., Unden, A., \& Nordlander, R. (1999). Improved physical fitness and quality of life following training of elderly patients after acute coronary events. A 1 year follow-up randomized controlled study. Eur Heart J, 20(20), 1475-1484.

[6] Ball, L. J., \& Birge, S. J. (2002). Prevention of brain aging and dementia. Clin Geriatr Med, 18(3), 485-503

[7] Fernandez-Prado, S., Conlon, S., Mayan-Santos, J. M., \& Gandoy-Crego, M. (2011). The influence of a cognitive stimulation program on the quality of life perception among the elderly. Arch Gerontol Geriatr.

[8] Uchida, S., \& Kawashima, R. (2008). Reading and solving arithmetic problems improves cognitive functions of normal aged people: a randomized controlled study. Age (Dordr), 30(1), 21-29.

[9] Willis, S. L., Tennstedt, S. L., Marsiske, M., Ball, K., Elias, J., Koepke, K. M., et al. (2006). Long-term effects of cognitive training on everyday functional outcomes in older adults. $J A$ MA, 296(23), 2805-2814.

[10]Zelinski, E. M., Spina, L. M., Yaffe, K., Ruff, R., Kennison, R. F., Mahncke, H. W., et al. (2011). Improvement in memory with plasticity-based adaptive cognitive training: results of the 3-month follow-up. J Am Geriatr Soc, 59(2), 258-265.

[11]Kamenetz, F., Tomita, T., Hsieh, H., Seabrook, G., Borchelt, D., Iwatsubo, T., et al. (2003). APP Processing and Synaptic Function. Neuron, 37(6), 925-937.

[12]Lazarov, O., Robinson, J., Tang, Y.-P., Hairston, I. S. Korade-Mirnics, Z., Lee, V. M. Y., et al. (2005). Environmental Enrichment Reduces A $\beta$ Levels and Amyloid Deposition in Transgenic Mice. Cell, 120(5), 701-713.

[13]Burdick, D. C., \& Kwon, S. (2004). Gerotechnology: research and practice in technology and aging : a textbook and refer- ence for multiple disciplines. New York, NY: Springer Pub. Co.

[14] Rapporto annuale (2002). L'Italia dell'e-Family., a cura della Federcomin-Anie (Eds.)- Indagine sulle famiglie italiane, Primo Rapporto, Febbraio 2003, curato da Between

[15]Fubini, E. (2010). Ergonomia antropologica (Vol. 2). Milano: Franco Angeli.

[16]Östlund, B. 2004 Social Science Research on Technology and the Elderly-Does it Exist?

[17] Green, C. S., \& Bavelier, D. (2006). Enumeration versus multiple object tracking: the case of action video game players. Cognition, 101(1), 217-245.)

[18] Gorini, A.,Gaggioli, A., \&Riva, G. (2006). Virtual Wolds. Science, 318(5856), 1549

[19]Riedl, M. O., \& Young, R. M. (2004). An Intent-Driven Planner for Multi-Agent Story Generation. Paper presented at the Proceedings of the Third International Joint Conference on Autonomous Agents and Multiagent Systems - Volume 1.

[20]Barr, P., Noble, J., \& Biddle, R. (2007). Video game values: Human-computer interaction and games. Interacting with Computers, 19(2), 180-195.

[21]Bahr, R. \& Bahr, I. A. (1997). Incidence of acute volleyball injuries: a prospective cohort study of injury mechanisms and risk factors. Scandinavian Journal of Medicine \& Science in Sports, 7(3), 166-171.

[22]Emery, C.A., Cassidy, D., Klassen, T.P., Rosychuk, R.J., Rowe, B.H. (2005). Effectiveness of a home-based balancetraining program in reducing sports-related injuries among healthy adolescents: a cluster randomized controlled trial. CMAJ, 172(6), 749-754

[23] Colcombe, S. J., Kramer, A. F., McAuley, E., Erickson, K. I., \& Scalf, P. (2004). Neurocognitive aging and cardiovascular fitness: recent findings and future directions. $J$ Mol Neurosci, 24(1), 9-14

[24]Bisson, E., Contant, B., Sveistrup, H. \& Lajoie, Y. (2007). CyberPsychology \& Behavior, 10(1): 16-23

[25] Wada, K., Shibata, T. Saito, T., Sakamoto, K. \& Tanie, K. (2005). Psychological and Social Effects of One Year Robot Assisted Activity on Elderly People at a Health Service Facility for the Aged. Robotics and Automation, Proceedings of the 2005 IEEE International Conference on, 2005a: p. 2785-2790

[26] Browne, H. 2000. Accessibility and usability of information technology by the elderly. Universal Usability Guide. Retrieved June 10, 2004 http://www.otal.umd.edu/UUGuide/hbrowne/

[27]Miller, J. R., Lerner, R. R., Schiamberg, L. B., \& Anderson, P M. (Eds.). (2003). Encyclopedia of human ecology. Santa Barbara, CA: ABC-Clio

[28] Cesta, A., Cortellessa, G., Giuliani, M. V., Pecora, F., Scopelliti, M., \& Tiberio, L. (2007). Psychological Implications of Domestic Assistive Technology for the Elderly. PsychNology Journal, 5(3), 229 - 252

[29] ISO 18529/2000

[30] Tosi, F. (2006). Ergonomia e progetto. Milano: Franco Angeli

[31] Sharp, H., Rogers, Y., \& Preece, J. (2007). Interaction Design: Beyond Human-computer Interaction (2nd ed.). West Sussex: John Wiley \& Sons, Ltd

[32]UNI EN ISO 9241-11:2002

[33] Cardano, M. (2011). La ricerca qualitativa. Bologna: Il Mulino.

[34] Schensul, S. L., Schensul, J. J., \& LeCompte, M. D. (1999). Essential ethnographic methods: observations, interviews, and questionnaires Oxford: AltaMira Press.

[35]Beyer, H., \& Holtzblatt, K. (1998). Contextual Design. Defining Customer-Centered Systems. San Francisco, CA: Morgan Kaufmann Publishers 
[36]Cardano, M. (2003). Tecniche di ricerca qualitativa. Percorsi di ricerca nelle scienze sociali. Roma: Carocci

[37]Babbie, E. R. (2009). The Practice of Social Research (12th ed.). Belmont, CA: Wadsworth.

[38] Cooper, A. (1999). Il disagio tecnologico. Perché i prodotti high-tech sono così difficili da usare e che cosa fare per migliorarli (A. Monti, Trans.). Milano: APOGEO.

[39]Carroll, J. M. (1995). Scenario-Based Design: Envisioning Work and Technology in System Development. Wiley.

[40]Carroll, J. M. (2000). Making use: scenario-based design of human-computer interactions. Cambridge, MA: MIT Press

[41] Rosson, M. B., \& Carroll, J. M. (2002). Usability engineering: scenario-based development of human-computer interaction. San Diego, CA: Academic Press 